\title{
Knowledge Representation of LMS using Ontology
}

\author{
H. Srimathi \\ Assistant Professor, Department of Computer Applications, \\ SRM University, Kattankulathur, 603203
}

\begin{abstract}
Personalization is the next step in the evolution of eLearning systems. Students can have several cognitive styles, which make the efficiency and efficacy of an eLearning system different with distinct students. The three different viewpoints [21] and evolution in the area of e-Learning are pedagogy (learneroriented educational theories), pragmatic (practical solutions to use of instructional components by teachers and instructional designers), and technological (building instructional components by computer professional). Though there are no distinct classifications of the approaches while implementing, the union of all the viewpoints is not dealt / applied completely by any of the author. This paper focus on integrating the above said principles on semantic educational servers with the power of eLearning standards. The knowledge items (learning objects) are linked to commonly agreed ontology [4], [7], [8]. This enables construction of a user-specific course, by semantic querying for topics of interest.
\end{abstract}

\section{Keywords}

Learning Object, Ontology, LMS, LCMS ,SCORM

\section{INTRODUCTION}

The success of e-Learning course material [17], [24] is based on the pedagogical principles. Few of the principles are curriculum design with specific objectives, consideration of different social groups, learner engagement, ease of use, and ensure the acquisition of learning objectives with formative and summative assessment. But due to over-focusing on technology and dissemination of content, it is less considered [1], [19], [20] which insists on learner centric guidelines for developing Learning Management System (LMS) and Learning Content Management System (LCMS).

The instructional design principles map educational pedagogy and information technology to best suit the learner. Though the application of instructional design helps on flexible design with suitable instructional activities, the translation of pedagogy into practice constitutes important challenges [14]. Also, most projects that defines Learning objects (LO) use the IEEE definition [13] which is a very vague definition, so that they are still evolving. A teacher experience can be embedded in LOs so that the course material is natural with ensuring high learning process [3]. The learner profile should be updated dynamically with the performance of the learner [16], which helps on identifying the dynamic lesson sequence.

The evolution in the field of Information Technology has made a frequent revision on implementing eLearning with the new innovations. The technology should be chosen which promises the promotion of personalization, distribution, creation and reusability of LO [21]. XML is the most promising technology to employ the specific parts of learning objects for the adaptation of the user centric cognitive styles with XSLT style sheets following the rule-based design pattern approach [22]. However there is a lack of formal semantics inherent in XML to achieve semantic interoperability [2], [5], [6].

Ontology based semantic web technologies are promising solution to give an explicit definition of conceptualization on a specified domain and assembling learning objects [25], [26]. The ontology integrated with the learner profile generates better results in an e-Learning LMS System [9] and could be used in combination with multi-agent technologies for deriving personalized learning paths instead of Directed Acyclic Graph [15]. The methodology that designs ontology using Protégé and content retrieval through web services is defined in [11] with the limitations of command line interface of implementation. Few of the study highlights the choice of SCORM [9], [18] one of the eLearning standards for implementing reusable, interoperable, and sequencing navigation of LO. The conceptual Service Oriented Architecture (SOA) of intelligent agent system is defined theoretically with the future focus of implementation feasibility [12].

The research addresses the lacunae present in the existing system with the need of integrated approach which combines all the three viewpoints. The objective of the research is "the design of LMS using LOs by applying Instructional Design principles, which will be elaborated with the latest technological revolution on defining educational intelligent server". The paper is organized as follows: Section 2 illustrates related work done in evolution of Learning Objects; Section 3 describes the ontology representation of LMS and its components with semantic querying.

\section{EVOLUTION OF LO IN LCMS}

LOs are elements of a new type of computer-based instruction grounded in the object-oriented paradigm of computer science. They are generally understood to be digital entities deliverable over the Internet, meaning that any number of people can access and use them simultaneously (as opposed to traditional instructional media, such as an overhead or video tape, which can only exist in one place at a time). Instructional designers can build small (relative to the size of an entire course) LO that can be reused a number of times in different contexts. Moreover, those who incorporate learning objects can collaborate on and benefit immediately from new versions. This is a significant difference between LO and other types of instructional media that have existed previously.

Few of the learning standards are evolved to facilitate the widespread adoption of the learning objects approach. Learning 
Technology Standards Committee (LTSC) of the IEEE has promoted IEEE LOM (Learning Object Meta data) [27]. Some of the other learning standards are Instructional Management Systems (IMS) and Shareable Content Object Reference Model (SCORM) developed by Advanced Distributed Learning (ADL). SCORM appears to be the most popular among all because it adopts all the above standards and specifications to provide a comprehensive suite of eLearning capabilities that enable interoperability, accessibility and reusability of web-based learning content [23]. Its practical implementation model is offering open java-based run-time environment. Also it is possible to form SCORM compliant LMS to deliver a consistent sequencing of course content. The various broad and vague definition of LO and less consideration of pedagogical principle in SCORM has insisted the identification and exploration of more learning objects which ensures high user interactivity and learning adaptation.

The ontological mapping is done between educational pedagogy and information technology components at various level as shown in Fig 1. The study is made by applying instructional design principles to map the components. The object properties to define the mapping are described in Fig. 2 and lead to set of learning objects of LCMS as shown in Fig 3. The identified LO promotes user interaction and learner adaptation. The sample LO created with the help of Adobe tools based on SCORM standards and manifest file created are listed in Fig 4 and Fig 5 respectively. But the learning content is a part of whole eLearning process which insists on integrated LMS dealt in section 3 .

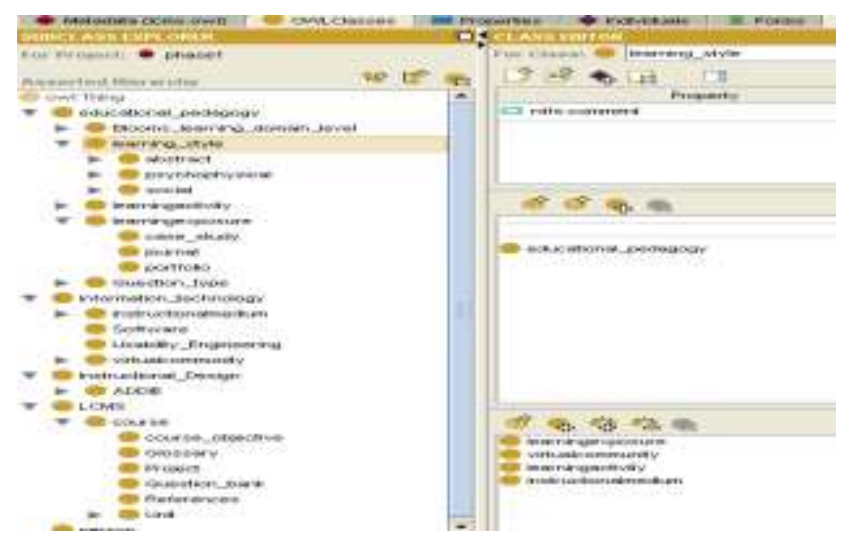

Figure 1. Instructional Design mapping of components using OWL ontology in Protégé

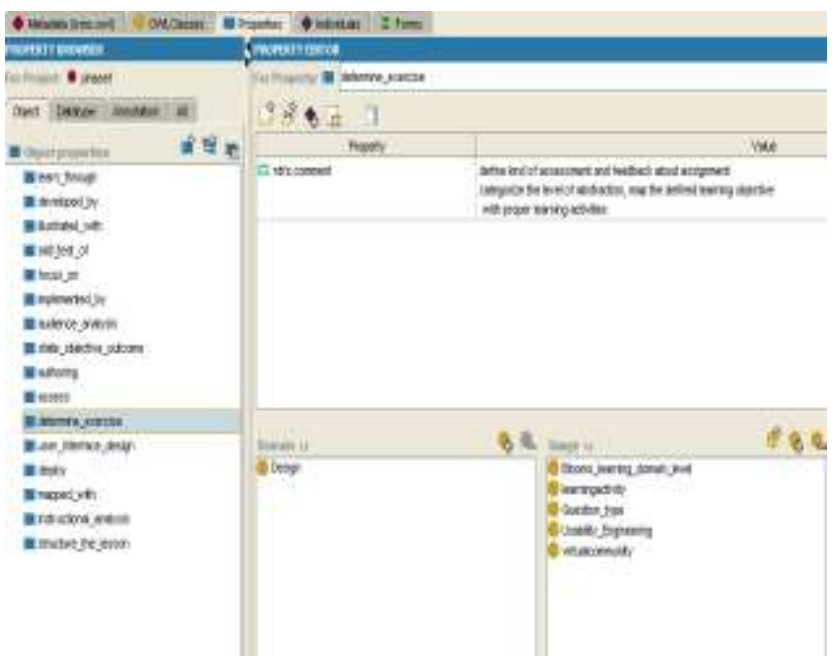

Figure 2. The set of object properties which are used to establish the mapping

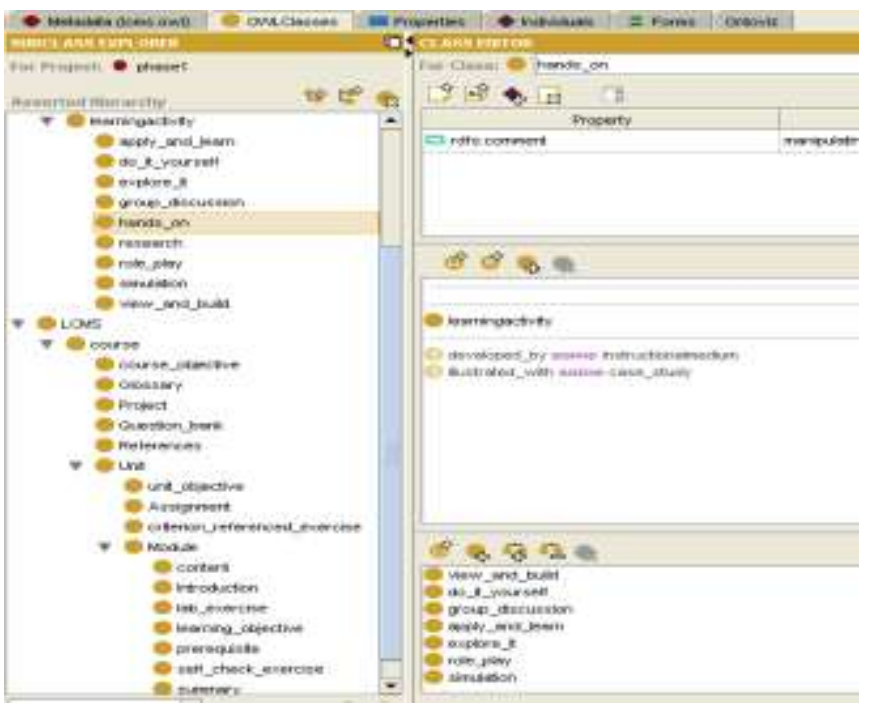

Figure 3. Variety of learning activities with LO hierarchy of LCMS

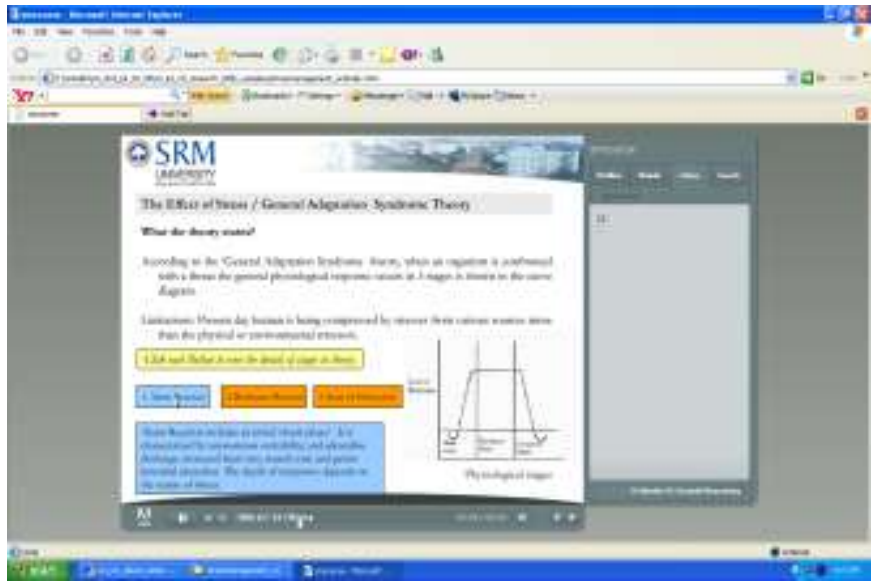

Figure 4. Sample LO 


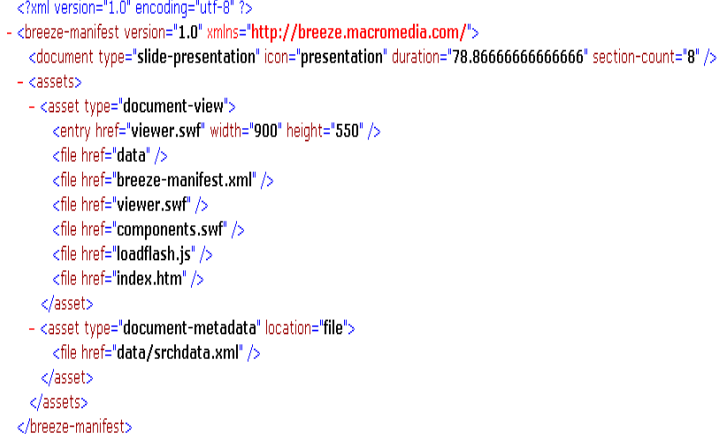

Figure 5. Manifest file of LO

\section{LMS ONTOLOGY}

The LCMS is one of the sub components in LMS which promotes a complete integration of eLearning system. Learning Management System is a program that manages the administration of complete on-line education. Learning Management System provides authoring, sequencing, and aggregation tools that structure the content to facilitate the learning process. The ontology representation of LMS in Fig 6. In order to personalize learning, the identified LOs are sequenced and navigated based on learner profile and their dynamic response. The learning is achieved by learning control flow defined by SCORM as shown in Fig 8 and Fig 9.

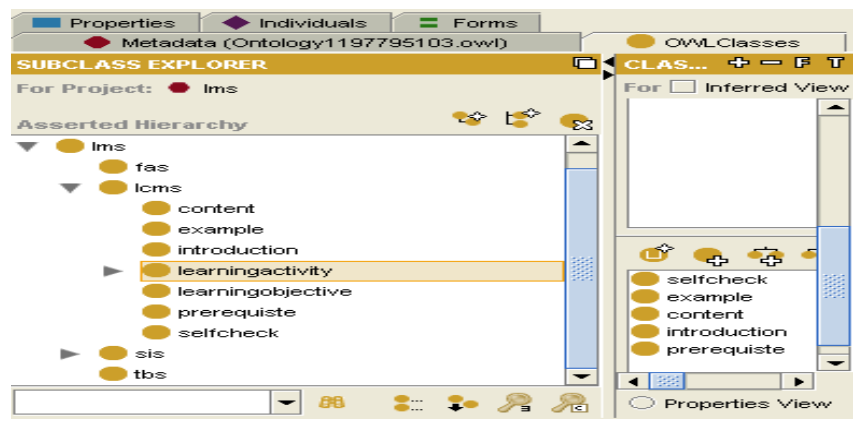

Figure 7. LMS and its components in Ontology

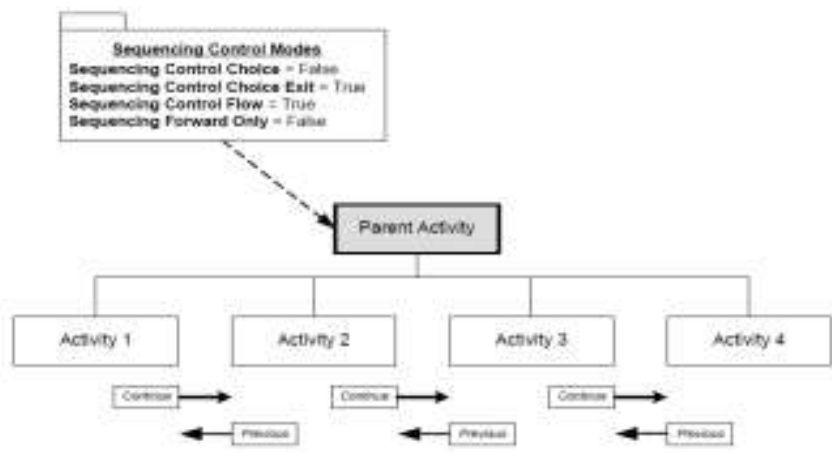

Figure 8. Learning Sequencing with repeat option based on user response (Source: SCORM 2004)

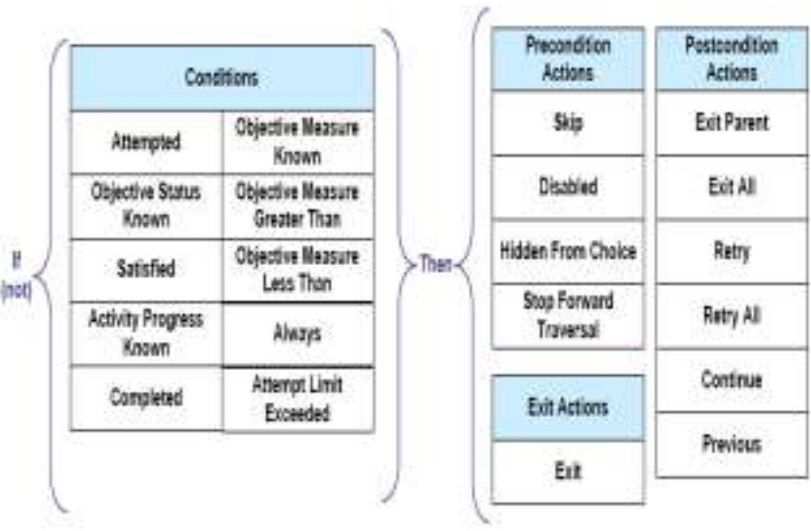

Figure 9. Sequencing conditions and rules enforced by SCORM (Source SCORM 2004)

\section{CONCLUSION}

This paper summarizes the benefit of integrating learning standards, id principles with the semantic web technology. The novelty of the work is personalization of learning activity based on learner performance without proposing any modification of existing SCORM services nothing but the variety of learner friendly learning objects. The future work concentrates on integration of existing learning objects available on the web.

\section{REFERENCES}

[1]. Akpinar, Y. and Simsek, H. (2005), "Development of a learning content management system based on interactive learning object approach", Int. Conf. on Information Technology Based Higher Education and Training, ITHET, pp. T3A5-T3A15

[2]. Berners-Lee, T. (2000), "What the Semantic Web can represent”, http://www.w3.org/DesignIssues/RDFnot.html

[3]. Blochl, M., Rumetshofer, H. and Woß, W. (2003), "Individualized E-Learning Systems Enabled by a Semantically Determined Adaptation of Learning Fragments", Int. Workshop on Database and Expert Systems Applications (DEXA), pp. 640-645.

[4]. Busetti, E., Forcheri, Ierardi, M.G. and Molfino, M.T. (2004), "Repositories of LOs as Learning Environments for Teachers", IEEE Int. Conf. on Advanced Learning Technologies (ICALT), pp. 450-454.

[5]. Decker, S., Melnik, S., VanHarmelen, H., Fensel, D., Klein, M., Broekstra, J., Erdmann, M. and Horrocks, I. (2000), "The Semantic Web: The Roles of XML and RDF ", IEEE Internet Computing, 4 (5), pp. 63-74.

[6]. Devedzic, V (2004), "Web Intelligence and Artificial Intelligence in Education", Educational Technology and Society, 7(4), pp. 29-39.

[7]. Gasevic, D., Jovanovic, J. and Devedzic, V. (2004), "Enhancing Learning Object Content on the Semantic 
Web", IEEE Int. Conf. on Advanced Learning Technologies (ICALT), pp. 714-716.

[8]. Guo, W. and Chen, D. (2006), "Semantic Approach for eLearning System", Int. Multi-Symposia on Computer and Computational Sciences (IMSCCS), pp. 442-446.

[9]. Heiyanthuduwage, S.R. and Karunaratne, D.D (2006), "A Learner Oriented Ontology of Metadata to improve Effectiveness of Learning Management Systems", Int. Conf. on eLearning for Knowledge-Based Society, http://www.elearningap.com/eLAP2006/ Proceeding/p42.16-fin-12.pdf.

[10].Henze, N., Dolog, P. and Nejdl, W. (2004), "Reasoning and Ontologies for Personalized E-Learning in the Semantic Web", Educational Technology and Society, 7 (4), pp. 8297.

[11].Hogeboom, M., Lin, F., Esmahi, L. and Yang, C. (2005), "Constructing knowledge bases for E-Learning using Protégé 2000 and Web Services", Int. Conf. on Advanced Information and Networking Applications (AINA), pp. 215220 .

[12].Hussain, N. and Khan, M.K. (2005), "Service Oriented ELearning Architecture using Web Service-based Intelligent Agent" Int. Conf. on Information and Communication Technologies (ICICT), pp. 137 - 143.

[13].IEEE LOM, (2002), "IEEE standard for Learning object Metadata", http://ltsc.ieee.org/wg12.

[14].Karagiorgi, Y. and Symeou, L. (2005), "Translating Constructivism into Instructional Design: Potential and Limitations", Educational Technology and Society, 8 (1), pp. 17-27.

[15].Keleberda, I., Lesna, N., Makovetskiy, S. and Teriziyan, V. (2004), "Personalized Distance Learning Based on Multiagent Ontological System", IEEE Int. Conf. on Advanced Learning Technologies (ICALT), pp. 777-779.

[16].Knight, C., Gasevic, D. and Richards, G. (2005), "Ontologies to integrate learning design and learning content", Journal on Interactive Media in Education, http://www-jime.open.ac.uk/2005/07/knight-2005-07.pdf .

[17].Norhayati, A.M. and Siew, P.H. (2004), "Malaysian Perspective: Designing Interactive Multimedia Learning Environment for Moral Values Education", Educational Technology and Society, 7 (4), pp. 143-152.
[18].Paulo, G., Antunes, B. Luis, and Rodriguez (2006), "Using Ontologies for elearning Personalization", $3^{\text {rd }}$ E-Learning Conf. http://www.formare.pt/documentos/artusingontologies for_elearning_perso.pdf.

[19]. Raghavan, R. (2001), "LCMS and LMS, Taking advantage of Tight Integration", http://www.elearn.cz/soubory/lcms_and_lms.pdf.

[20]. Ronchetti, M. and Saini, P. (2004), "Knowledge Management in an E-learning System", IEEE Int. Conf. on Advanced Learning Technologies (ICALT), pp. 365-369.

[21]. Rossano, V., Joy, M., Roscelli, T. and Sutinen, E. (2005), "A Taxonomy for Definitions and Applications of LOs: A Meta-analysis of ICALT papers", Educational Technology and Society, 8(4), pp. 148-160.

[22].Rumetshofer, H. and Wob, W. (2003), "XML-based Adaptation Framework for Psychological-driven E-Learning Systems", Educational Technology and Society, 6(4), pp. 18-29.

[23].SCORM (2004), "Sharable Content Object Reference Model (SCORM)", http://adlnet.org

[24].Siew, W.L., Khong, C.W, and Lee, C.S. (2001), “An Evolving Instructional Design Model for Designing WebBased Courses", IEEE Int. Conf. on Advanced Learning Technologies, (ICALT), pp. 443-444.

[25]. Stojanovic, L.j., Staab, S. and Studer R (2001), "eLearning based on the semantic web", Proceedings of WWWnet Conf., http://www.aifb.unikarlsruhe.de/ sst/Research/Publications/WebNet2001eLear ningintheSemanticWeb.pdf.

[26]. Valencia, L., Novarro, A., Aedo, I. and Kloos, C. (2005), "An ontology based mechanism for assembling learning objects", Advanced Industrial Conf. on Telecommunications/Service Assurance/Elearning, pp. 472 477.

[27]. Yang C, Hsin-Chuan Ho, A Shareable e-Learning Platform using Data Grid Technology,. IEEE apos;05. Proceedings. The 2005 IEEE International Conference e-Technology, eCommerce and e-Service. pp. $592-595$ 